\title{
AVALIAÇÃO DE PRODUÇÃO ESCRITA: UM OLHAR DOCENTE E UM OLHAR SURDO*
}

Soraya Gonçalves Celestino Silva

Evangelina Maria Brito de Faria

Fábia Sousa de Sena

Marianne Carvalho Bezerra Cavalcante

\section{Introdução}

Neste capítulo, procuramos discutir dados de pesquisas que abordaram a escrita do português pelo surdo. De um lado tem-se a visão do docente, do outro, do próprio aluno surdo. Relacionar esses dois olhares apontou para surpresas. Como referências, utilizamos dados de duas pesquisas $^{1}$ : a primeira de Silva (2015), sobre a avaliação da língua portuguesa para o aluno surdo. Na segunda de Sena (2017), sobre o letramento do aluno surdo na escola regular: perspectivas e desafios. Nas pesquisas, foram realizadas entrevistas com três professores de duas escolas inclusivas E1 e E2, e aplicação de questionários com nove alunos surdos distribuídos no Ensino Fundamental II e na Educação de Jovens e Adultos (EJA), em escolas públicas municipais de Pernambuco e da Paraíba.

Esses estudos são decorrências de várias conquistas em relação aos direitos de surdos no âmbito educacional. Há pouco tempo, foi reconhecido o direito de comunicação na modalidade específica de linguagem dos surdos, a Libras, que foi oficializada com a publicação da LEI № 10.436 de 24 de abril de 2002, estabelecendo-a, como língua materna do surdo e como segunda língua, a língua Portuguesa, em sua modalidade escrita. O Decreto № 5.626 de 22 de dezembro de 2005, regulamentou essa lei e garantiu apoio ao seu uso e difusão, bem como determinou seu ensino em âmbito nacional. Foi uma grande mudança.

\footnotetext{
"DOI - 10.29388/978-65-86678-60-4-0-f.329-354

${ }^{1}$ SILVA, Soraya. Avaliação da língua portuguesa para o aluno surdo: experiências em escolas públicas municipais de Pernambuco. Proling/UFPB, 2015; Sena, Fábia. O letramento do aluno surdo na escola regular: Perspectivas e Desafios. Proling/UFPB, 2017.
} 
Também o processo de avaliação passou por transformações em sua concepção. No passado, a avaliação era usada como instrumento para classificar e rotular os alunos. Hoje, há uma concepção diferenciada. Para Batista (2005), a avaliação diagnóstica é o ponto de partida do trabalho pedagógico; sobretudo para um trabalho pedagógico autônomo, em que o professor controla o que ensina, para que ensina e o como ensina.

Como se vê, a avaliação tornou-se muito mais um movimento para estruturar a ação do professor em direção ao desenvolvimento das habilidades dos alunos. Naturalmente, essa nova visão ainda não se concretizou totalmente na sala de aula. Contribui Hoffmann (2013, p. 36), nessa linha de raciocínio, ao afirmar que "a avaliação se configura gradativamente mais problemática na educação na medida em que se amplia a contradição entre o discurso e a prática dos educadores".

De um modo geral, o processo de avaliação como um todo é problemático pois, como afirmou Hoffmann, a prática ainda não se encontra sedimentada na teoria proposta, que é relativamente nova. $E$ isso diz respeito tanto à avaliação de alunos surdos ou ouvintes. Contudo, nossas discussões serão bem pontuais: Que estratégias são utilizadas em sala de aula para avaliação do aluno surdo? Quais os retornos dessa avaliação? Como o professor se vê como avaliador da produção textual do surdo? Como o aluno surdo concebe a Língua Portuguesa e seu uso?

Para o professor, é imprescindível saber avaliar e refletir sobre as hipóteses, estratégias, erros e acertos desses alunos surdos, pois essa reflexão é fundamental para que novas ações sejam planejadas durante o ensino e a aprendizagem deles.

\section{O letramento do aluno surdo em língua portuguesa como $L 2$}

Em termos psicolinguísticos, a primeira língua da criança é sempre uma língua natural. As crianças ouvintes precisam aprender o português, língua oral-auditiva, para isso faz-se apenas necessário que ela esteja em contato com pessoas que falam. 0 mesmo acontece com as crianças surdas, que necessitam do contato com surdos adultos ou ouvinte que utilizem a Libras, língua visual.

A aquisição da Língua Portuguesa por crianças surdas, além de condição estabelecida por lei, é uma necessidade existente em nossa 
sociedade, uma vez que esse surdo está inserido numa comunidade de ouvintes, falantes da língua portuguesa. No entanto, apesar dos alunos surdos serem brasileiros, eles só aprenderão o português, caso não sejam filhos de pais surdos, se submetidos a um processo formal, com metodologias específicas e professores especializados para este fim. Portanto, sua L1 (natural) será a Libras e a Língua Portuguesa será aprendida como L2 (segunda língua). Duas línguas distintas: a Libras tem características próprias, sendo a principal delas ser uma Língua gestual-visual, ou seja, uma língua que utiliza o canal visual e as expressões faciais e corporais na construção do sentido, já o português, caracteriza-se por ser uma língua que tem por base a relação com o som.

Para a construção desse currículo bilíngue que contemple a aprendizagem da língua portuguesa em sua modalidade escrita pelo surdo, é importante que o professor utilize metodologias diferenciadas com a finalidade de um processo de alfabetização exitosa, na qual a língua portuguesa seja significada pelos sujeitos surdos, o que não é uma tarefa simples para o professor, uma vez que o ensino de língua portuguesa para alunos surdos é um desafio constante, por se tratar de uma segunda língua.

Nessa perspectiva, o ensino da língua oficial do nosso país, ou seja, da língua portuguesa, como segunda língua para surdos, na modalidade escrita, baseia-se no fato de que os sujeitos surdos são cidadãos brasileiros e possuem o direito de utilizar e aprender a referida língua, pois é importante para o exercício de sua cidadania.

Assim, o ensino para o sujeito surdo deverá ser bilíngue e a escola é a instituição responsável para o cumprimento dessa lei vigente no país. De acordo com Quadros e Schmiedt (2006),

A língua de sinais também apresenta um papel fundamental no processo de ensino-aprendizagem do português. A ideia não é simplesmente uma transferência de conhecimentos da primeira língua para a segunda língua, mas sim um processo paralelo de aquisição e aprendizagem em que cada língua apresenta seus papéis e valores sociais representados (QUADROS E SCHMIEDT, 2006, p. 24).

A aprendizagem da língua portuguesa deve fazer parte do currículo do sujeito surdo e as escolas devem ter sensibilidade para compreender a condição linguística desse sujeito, tendo em vista que a fluência em sua língua 
materna é um fator considerado importante para a aquisição da segunda língua. Porém, é bastante comum encontrarmos em sala de aula do ensino regular a prática de uma dinâmica voltada para a língua oral e escrita (LACERDA; LODI 2014, p. 17), o que ocasiona uma grande dificuldade do aluno surdo em participar das atividades realizadas na sala de aula, e apesar da condição do intérprete, o sujeito surdo se põe em condição de desvantagem, sendo essa lacuna refletida nas avaliações realizadas pelos educadores. Já vimos que o ensino é problemático, e a avaliação?

\section{Avaliação da língua portuguesa como L2}

A educação inclusiva é uma realidade na educação brasileira e deve proporcionar ao aluno surdo a garantia do seu acesso ao processo de ensinoaprendizagem de forma plena e igualitária. Muitos professores defendem que é preciso tratar todos os alunos igualmente, mas, ao raciocinarem desse modo, reproduzem atitudes excludentes.

As escolas precisam se conscientizar de que o português é a L2 para o surdo e que esta tem que ser ensinada como L2 e não como L1 como fazem com os alunos ouvintes tomando como base a oralidade. Colaboram Thoma e Klein $(2009$, p.99) ao afirmar que "o sucesso ou fracasso escolar do aluno se relaciona diretamente com as imagens e representações que dão ao surdo certas dificuldades de aprendizagem, ligadas a uma suposta inferioridade cognitiva e linguística". Desse modo, o fracasso escolar do surdo está, muitas vezes, na forma como é conduzido o ensino da leitura e da escrita da língua portuguesa.

Essa inclusão não pode partir da igualdade de acesso tendo como base a língua de instrução que é o português. Sobre a inclusão de alunos surdos, Hoffmann (2009) afirma que:

[...] são aprendizagens diferentes. Neste sentido, diferenciar não significa subestimar, mas cuidar do jeito que cada uma precisa. E essa diferenciação se estende ao acompanhamento do professor, a análise das manifestações dos estudantes que deve se dar a partir das condições próprias do contexto educativo e de formas de divulgação dos seus desempenhos ao longo do processo (HOFFMANN, 2009, p. 44). 
Não se pode negar que, por mais espaços que os surdos tenham conquistado, os discursos advindos da cultura ouvinte continuam a narrar os surdos pelo viés da limitação e da incapacidade, determinando os lugares que devem e os que não devem ocupar. Camillo (2009) diz que:

\begin{abstract}
A avaliação se inscreve numa rede discursiva, colocando os alunos como alvos de estratégias disciplinadoras que investem constantemente na normalização, correção, na regulação dos corpos através de vigilância e punição. Ao colocar-se na vitrine a avaliação na educação de surdos, é possível entender como se produzem "verdades" sobre alunos no espaço da escola e discutiras estratégias disciplinares envolvidas nas práticas avaliativas (CAMILLO, 2009, p.69).
\end{abstract}

Conforme Camillo, a avaliação não tem ajudado o surdo a desenvolver suas habilidades linguísticas, mas continua a serviço de uma permanência do rótulo da incapacidade de apender a língua. Dentre os documentos que asseguram aos aprendizes surdos uma avaliação diferenciada em português por escrito, sublinha-se o Decreto Federal no 5.626/2005 no seu Art. 14. § 10 Incisos VI e VII, o qual considera que alunos surdos têm direito a uma avaliação diferenciada, apresentando em seu texto o seguinte:

VI - Adotar mecanismos de avaliação concretos com aprendizado de segunda língua, na correção de provas escritas, valorizando o aspecto semântico e reconhecendo a singularidade linguística manifestada no aspecto formal da língua portuguesa;

VII - desenvolver e adotar mecanismos alternativos para a avaliação de conhecimento expressões em Libras, desde que devidamente registrados em vídeos ou em outros meios eletrônicos e tecnológicos.

É de responsabilidade da escola e do professor traçar objetivos para cada aluno surdo, definir mediante o nível de escolarização quais estratégias e vocabulários que devem conter na produção textual desses alunos. Para então, definir critérios de avaliação, sem deixar de considerar a língua portuguesa como L2. É relevante que o professor tenha um olhar diferenciado na hora de avaliar e refletir sobre as hipóteses, estratégias, erros e acertos, pois essa reflexão é fundamental para que novas ações sejam planejadas durante o ensino e a aprendizagem. 
A avaliação da produção textual do surdo deve ter uma metodologia que deverá ser explicada e discutida com o próprio aluno surdo, cabendo ao professor chamar atenção para os aspectos diferenciados nas produções escritas e proceder a reescrita dos textos, demonstrando a norma-padrão da língua, permitindo ao aluno, através de atividades linguísticas, perceber as diferenças entre a estrutura da Libras e da Língua Portuguesa. Essas mesmas atividades deverão ser tomadas como parâmetro para acompanhar a evolução do seu processo de aprendizagem.

Bolsanello e Ross (2005) propõem que o professor, ao avaliar um texto produzido por alunos surdos, tenha em mente determinadas diretrizes:

a. Procure valorizar o conteúdo desenvolvido, buscando a coerência em sua produção, mesmo que a estrutura frasal não corresponda aos padrões exigidos para o nível/série em que se encontra;

b. Verifique se o uso de palavras aparentemente inadequadas ou sem sentido não indica um significado diverso do pretendido pelo aluno;

c. Considere os possíveis equívocos em relação ao uso de tempos verbais e a omissão ou inadequação do uso de artigos, preposições, decorrentes do desconhecimento da língua portuguesa ou da interferência da Libras;

d. Compreenda que o vocábulo "pobre" ou limitado, deve-se às poucas experiências significativas com a língua portuguesa que viveu;

e. Utilize as próprias produções do aluno para avaliar seu progresso, evitando comparações com os demais alunos (BOLSANELLO; ROSS, 2005, p. 18).

Queremos dar relevo, principalmente, ao último item, que trata da comparação entre textos do próprio aluno, para verificar seu desenvolvimento linguístico. Desta forma, os professores podem mensurar o conhecimento adquirido pelos alunos, tomando como base a avaliação inicial e as atividades realizadas nas avaliações processuais, podendo extrair o máximo de subsídios para conhecimento sobre a caminhada de cada aluno. Uma vez identificados os problemas, eles servirão para planejamento e implementação de estratégias para superação. Contribuem Faria e Assis (2012) para necessidade de que o professor avalie e analise os textos escritos pelos alunos, para listar os "erros", classificá-los (estabelecendo uma tipologia, a frequência com que ocorrem e as prováveis causas) e elaborar estratégias pedagógicas para auxiliar 
os alunos a superá-los. Desta forma, os professores podem melhorar a validade do processo da aprendizagem através de suas avaliações.

Para planejar e realizar atividades de avaliação para alunos surdos, entendem Russel \& Airasian (2014) que os professores devem estar cientes das adequações específicas requeridas para sua especificidade. As quais podem se utilizar de diversos tipos de acomodações tais como:

- Modificar o formato da apresentação da avaliação: usar orientações escritas, em vez de orais; olhar para o aluno quando este estiver falando; usar língua de sinais; fornecer materiais visuais (fluxograma, imagens, tabelas etc.) e fazer pré-leitura da pergunta;

- Modificar o formato das respostas: fornecer exemplo de respostas esperados; permitir o uso de calculadora, textos e dicionários; fazer uma avaliação semelhante ao que foi ensinado em sala durante as aulas e verificar mais de uma vez se o aluno entendeu as questões e as respostas desejadas;

- Modificar o tempo da avaliação: oferecer tempo extra; oferecer intervalo extra durante a prova, se necessário;

- Modificar o ambiente da avaliação: colocar o aluno longe de distrações; aplicar a prova em local silencioso e separado, quando necessário (RUSSEL \& AIRASIAN, 2014, p. 181).

Todas essas categorias incluem muitas das acomodações mais comuns utilizadas em sala de aula. Colaboram os autores (2014) ao dizer que "os professores devem mostrar sensibilidade às percepções que os alunos têm uns dos outros e, portanto, tornar suas avaliações e seus procedimentos modificados os mais acessíveis quanto possível, de forma a não chamar atenção para as diferentes necessidades desses alunos surdos".

Sobre as estratégias e procedimentos para a avaliação da aprendizagem escolar do aluno surdo, Bolsanello e Ross (2005) estabelecem algumas estratégias a seguir: 
Tabela 1: Estratégias e procedimento para avaliação da aprendizagem escolar do aluno surdo

Na leitura e na interpretação do texto: aplicam-se a todas as áreas do conhecimento, pois todas elas consideram Língua Portuguesa em sua organização.

a) Todas as atividades de leituras devem ser contextualizadas em referências visuais que permitam aos alunos uma compreensão prévia do tema implicado.

b) $\mathrm{Na}$ interpretação de textos, permitir o uso de diferentes linguagens: artes plásticas (desenho, pintura, escultura, murais e maquetes) e cênicas (teatro, dramatização e mímica);

c) Não solicitar a leitura em voz alta por razões óbvias;

d) Permitir a resposta na forma de linguagem utilizada pelo aluno, seja a L1 ou gestual natural.

Na elaboração de exercícios e questões: procurar evitar a utilização de questões que exijam apenas respostas escritas. A elaboração do enunciado é fundamental, simplifique-o, evite construções muito longas e pouco objetivas.

Utilize: De acordo com a necessidade, exemplificando:

a) Pinte os desenhos que mostram os cuidados com o meio ambiente;

b) Ligue o menino aos bons cuidados com o meio ambiente;

c) Enumere com 1(BONS) e 2 (MAUS) cuidados com o meio ambiente;

d) Marque com um $X$ as alternativas certas;

e) Desenhe alguns cuidados com o meio ambiente.

De modo geral:

a) Planeje atividades com diferentes graus de dificuldades e que permitam diferentes possibilidades de execução (pesquisa, questionários, entrevistas etc.) e expressão (apresentação escrita, desenho, dramatização e maquetes);

b) proponha várias atividades para trabalhar um mesmo conteúdo. Ex.: vivências, observações, leituras, pesquisa, construção coletiva etc.;

c) combine diferentes tipos de agrupamentos de alunos, facilitando a visualização do aluno surdo e sua consequente integração com os colegas (círculo, duplas e grupos).

Fonte: Bolsanello; Ross (2005, p. 20)

Percebemos que os autores Airasian e Russel (2014) e Bolsanello e Ross (2005) comungam da necessidade do uso de acomodações ou estratégias de acordo com nomenclatura usada por cada um. O que devemos ter em mente é que todos os conteúdos, que têm como pré-requisito a oralidade ou a percepção auditiva para sua compreensão, precisam de recursos visuais para que se efetive a aprendizagem do aluno surdo. Não há uma sala homogênea. Portanto, todas essas sugestões podem ser aplicadas aos alunos ouvintes ou não. O que se pretende é assegurar um olhar particular, que cada aluno seja contemplado na sua individualidade. Vejamos um pouco da metodologia utilizadas nas pesquisas. 


\section{Metodologia}

A metodologia utilizada nas pesquisas se caracterizou como qualitativa, de caráter descritivo e seus dados foram detalhados por meio da análise do conteúdo na perspectiva de Bardin (2011). Os corpora coletados foram constituídos por dados obtidos de duas pesquisas de mestrado: a de Silva (2015), sobre a avaliação da língua portuguesa para o aluno surdo e a de Sena (2017), sobre o letramento do aluno surdo na escola regular: perspectivas e desafios.

Na primeira, sobre a avaliação, participaram da pesquisa três docentes de Língua Portuguesa, que receberam os codinomes Carla, Bruno e Aline, distribuídos em três turmas regulares do 50 ano do Ensino Fundamental, em escolas inclusivas representadas pelas siglas E1 - Olinda e E2 - Paulista. As análises dos dados foram discutidas através de trechos das narrativas dos entrevistados com os referenciais teóricos sendo distribuídos nas seguintes questões: 1) a quantidade de alunos surdos existentes na sala de aula; 2) o conhecimento dos professores sobre a estrutura da Libras; 3) como o professor avalia o aluno surdo; 4) quais estratégias utilizadas por ele para avaliar esse aluno; 5) que parâmetros utilizam para considerar o texto do aluno surdo e do aluno ouvinte e 6) como o professor se autodefine avaliando o texto do aluno surdo? As entrevistas foram transcritas, observando-se a fidedignidade às respostas dadas pelos professores participantes.

$\mathrm{Na}$ segunda, sobre o letramento do surdo, participaram da pesquisa nove alunos surdos distribuídos da seguinte forma: dois do 5을 ano, um no 6응 ano, um no 70 ano três no 80 ano, um no 9 ㅇ ano e um EJA. A pesquisa foi desenvolvida no município de João Pessoa, tomando como base uma escola polo de tempo integral que apresenta a proposta de bilinguismo. $O$ trabalho contou com vários instrumentos de coletas de dados para o alcance de seus objetivos, dentre eles a aplicação de um questionário aos noves alunos surdos, que será objeto de nossa discussão. As análises dos dados foram discutidas através do resultado quantitativo das respostas dos pesquisados com os referenciais teóricos, sendo distribuídos nas seguintes questões: 1) Qual a sua idade / e ano de escolaridade; 2) Qual a renda familiar; 3) Como você considera o seu português; 4) Você tem dificuldade com a Língua Portuguesa e 5) Como uso a língua portuguesa para a realização de atividades do dia a dia? 
Para uma melhor visualização, os dados foram organizados em duas categorias: as vozes que sustentam as avaliações e as vozes que produzem a escrita, e dispostos em tabelas e gráficos. Através dos dados queremos ter uma melhor compreensão dos objetos de estudo e seus resultados.

\section{Conhecendo vozes que sustentam as avaliações}

Discutiremos, a seguir, as respostas das entrevistas realizadas com os professores e transcreveremos conforme seus posicionamentos a fim de garantir a legitimidade do trabalho e a opinião desses profissionais.

Tabela 2 - Quantitativo de alunos surdos na sua sala regular

\begin{tabular}{|l|c|}
\hline PROFESSORES & QUANTITATIVO DE ALUNOS SURDOS \\
\hline Carla & 1 \\
\hline Bruno & 1 \\
\hline Aline & 1 \\
\hline
\end{tabular}

Fonte: Elaborada pelas autoras, 2016.

Vemos que não há uma grande demanda. Acredita-se que a quantidade de alunos surdos se mantém na média de um por sala, devendo-se ao fato do pouco tempo dessa inclusão no ensino regular. Destaca-se aqui o papel do professor, quanto ao trabalho desenvolvido em sala de aula, onde se faz necessário que sejam atendidas as especificidades destes alunos, havendo uma valorização de todas as diferenças, e que esta esteja pautada nos objetivos da educação, visando o exercício da cidadania e a preparação para ser inserido nos vários contextos sociais. Uma educação para todos.

A seguir verificaremos se o professor conhece a estrutura da Língua de Sinais:

Tabela 3 - O professor conhece a estrutura da Língua de Sinais

\begin{tabular}{|l|l|}
\hline PROFESSORES & CONHECE A ESTRUTURA DA LÍNGUA DE SINAIS \\
\hline Carla & $\begin{array}{l}\text { Sei que ela está dividida em três partes. A 1a que é a posição das mãos, a } \\
\text { 2a que é a estrutura do sinal em relação ao corpo e a terceira que é a } \\
\text { movimentação do sinal com o meio. }\end{array}$ \\
\hline Bruno & Sim, fiz vários cursos, mas não sei trabalhar. \\
\hline Aline & Sim, mas não sei trabalhar. \\
\hline
\end{tabular}

Fonte: Elaborada pelas autoras, 2016. 
Souza e Góes (1999) afirmam que o processo de inclusão do aluno surdo vem sendo acompanhado por professores e profissionais que desconhecem a Libras e as condições do bilinguismo do surdo, por esta razão se sentem despreparados para atuar com esses alunos. É o que percebemos nas respostas dos professores Bruno e Aline que, mesmo afirmando conhecer a estrutura da Libras, não sabem utilizá-la com os alunos. Apesar de Carla manifestar um conhecimento da estrutura, não deu informação sobre o trabalho com os alunos.

No Decreto $\mathrm{n} 05.262$ de 22 de dezembro de 2005, que regulamenta a Lei no 10.436, e trata da inclusão da Libras como disciplina curricular no seu

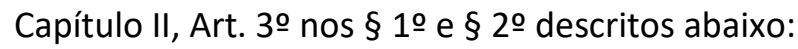

Art. $3^{\circ}$ A Libras deve ser inserida como disciplina curricular obrigatória nos cursos de formação de professores para o exercício do magistério, em nível médio e superior, e nos cursos de Fonoaudiologia, de instituições de ensino, públicas e privadas, do sistema federal de ensino e dos sistemas de ensino dos Estados, do Distrito Federal e dos Municípios.

$\S 1^{\circ}$ Todos os cursos de licenciatura, nas diferentes áreas do conhecimento, o curso normal de nível médio, o curso normal superior, o curso de Pedagogia e o curso de Educação Especial são considerados cursos de formação de professores e profissionais da educação para o exercício do magistério.

$\S 2^{\circ} \mathrm{A}$ Libras constituir-se-á em disciplina curricular optativa nos demais cursos de educação superior e na educação profissional, a partir de um ano da publicação deste Decreto.

Embora o referido decreto determine o ensino da Libras nos cursos de licenciatura no período de um semestre, percebemos que apenas um semestre não é o suficiente para a aprendizagem de uma nova língua e nem o capacita para ensiná-la. Da mesma forma que os professores graduados anteriormente ao decreto necessitam de um curso de Libras, os graduados posteriormente ao decreto deveriam também fazê-lo ou dispor rigorosamente do intérprete.

Questionamos aos participantes se o aluno surdo passava por uma avaliação diferenciada dos demais alunos e como era realizada esta avaliação. As respostas do questionário foram redigidas na íntegra na Tabela 3. Salientase que a intenção não foi julgar ou fazer comparações entre os professores, 
mas de perceber qual o entendimento de cada professor em relação ao tema: avaliação do aluno surdo.

Tabela 4 - Como os professores avaliam os alunos surdos

\begin{tabular}{|l|l|}
\hline PROFESSORES & COMO OS PROFESSORES AVALIAM OS ALUNOS SURDOS \\
\hline Carla & $\begin{array}{l}\text { Minha avaliação é processual e para isso anteriormente foi elaborado } \\
\text { um planejamento após conhecer o aluno e assim estabelecidas metas } \\
\text { para ele. E de acordo com o desenvolvimento do aluno, à medida que as } \\
\text { metas são alcançadas, vou Ihe atribuindo conceitos que, infelizmente, } \\
\text { depois tenho que dar notas. }\end{array}$ \\
\hline Bruno & Atividade em sala e prova coletiva. \\
\hline Aline & $\begin{array}{l}\text { Como ele está inserido no processo de alfabetização, esta avaliação é } \\
\text { feita diariamente observando os avanços na Libras, desenvolvimento da } \\
\text { escrita e tenho o apoio do intérprete de Libras. }\end{array}$ \\
\hline
\end{tabular}

Fonte: Elaborada pelas autoras, 2016.

Na Tabela 3, referente à avaliação dos alunos surdos, feita pelos professores, pode-se observar que as professoras Carla e Aline avaliam de forma diferenciada, como é determinado no Decreto- Lei 5.626/05 em seu Art. 14. § 1으, Incisos VI e VII, mencionado anteriormente. Em relação a Carla, vê-se que ela utiliza a produção do próprio aluno, conforme Bolsanello e Ross (2005). Ela parte da meta estabelecida para o próprio aluno. Se ele conseguiu atingir sua meta, será avaliado segundo seu processo evitando comparações com os demais alunos. Aline remete também para uma avaliação processual, observando o desenvolvimento da Libras e da Língua portuguesa, contando com o apoio do intérprete. Já Bruno cita apenas os recursos de que se utiliza para a avaliação. Pela sua resposta, não sabemos os parâmetros empregados para respaldar a avaliação, dá a entender que é a somativa, apenas para dar a nota.

De uma forma geral, percebe-se, por meio das respostas dos professores, que a forma com que eles avaliam seus alunos contribui para que não sejam punidos ou negligenciados por não saberem ler e escrever tal qual o aluno ouvinte, alfabetizado na Língua Portuguesa. Isso nos remete ao teórico Aquino (2007) quando nos fala da missão do professor, que é de levar o conhecimento e preparar cidadãos conscientes, deste modo, mais do que educar; a grande missão do professor é: fazer o aluno compreender o mundo em que vive e como ele se define nesse mundo, contribuir para a formação de um aluno consciente e crítico, capaz de atuar no presente e de ajudar a 
construir o futuro para uma sociedade mais justa e igualitária. Contribui Vygotsky (1991) ao afirmar que um professor empenhado em promover a aprendizagem de seu aluno tem que interferir em suas atividades psíquicas, notadamente em seu pensamento, pois é o aluno que dirige o seu próprio processo de aprender. No caso do aluno surdo, o professor precisa utilizar toda a sua capacidade e habilidade para conseguir atingir essa atividade acima citada, isto é, estimular o potencial que esse aluno possui.

$\mathrm{Na}$ atuação do professor, temos que levar em consideração que ele sempre planeja ações cujos objetivos e metas devem atingir ou refletir-se no aluno. Assim, buscaram-se entender nesta pesquisa quais estratégias os professores desenvolveram para atender o seu aluno surdo. A Tabela 4 demonstra estas estratégias.

Tabela 5 - Estratégias utilizadas para avaliar o aluno surdo

\begin{tabular}{|l|l|}
\hline PROFESSORES & ESTRATÉGIAS UTILIZADAS \\
\hline Carla & $\begin{array}{l}\text { A principal estratégia para a avaliação é ter a possibilidade de adaptar o } \\
\text { currículo de acordo com as necessidades do aluno, pois com o currículo } \\
\text { fechado é impossível avaliar o aluno surdo, haja vista as dificuldades de } \\
\text { interpretação e escrita que eles possuem. }\end{array}$ \\
\hline Bruno & $\begin{array}{l}\text { Utilização de figuras; o uso da Libras associada ao português escrito e o } \\
\text { auxílio do intérprete. }\end{array}$ \\
\hline Aline & $\begin{array}{l}\text { Observações; atividades de sondagem com auxílio de figuras; jogos; } \\
\text { brincadeiras e atividades de socialização. }\end{array}$ \\
\hline
\end{tabular}

Fonte: Elaborada pelas autoras, 2016.

Observando o que Airasian e Russel (2014) e Bolsanello e Ross (2005) explicitaram das acomodações ou estratégias para ajudar na avaliação, vemos que apenas três recursos foram contemplados nos discursos dos professores: a adaptação curricular, o uso da Libras e de imagens.

A professora Carla mencionou a questão da adaptação curricular, embora não tenha especificado nenhum exemplo concreto realizado para o aluno. De acordo com o documento oficial sobre estratégias para a educação de alunos com necessidades educacionais especiais, Brasil (2003, p. 34) nos esclarece bem quando afirma que:

[...] as adequações curriculares constituem possibilidades educacionais de atuar frente às dificuldades de aprendizagem dos alunos. Pressupõem que se realize a adequação do currículo regular, quando necessária, para 
torná-lo apropriado as peculiaridades dos alunos com necessidades especiais.

Não um novo currículo, mas um currículo dinâmico, alterável, passível de ampliação, para que atenda realmente a todos os educandos. Nessas circunstâncias, as adequações curriculares implicam a organização pedagógica e nas ações docentes fundamentadas em critérios que definam: o que o aluno deve aprender; como e quando aprender; que formas de organização do ensino são mais eficientes para o processo de aprendizagem; como e quando avaliar o aluno. Diante do exposto, a resposta fica vaga, sem termos condições de avaliar como a modificação curricular ajudou a inferir a aprendizagem em língua portuguesa.

O professor Bruno, por sua vez, relata a utilização de imagens (figuras) e da Libras para atender ao aluno surdo. Segundo Airasian e Russel (2014), o professor deve utilizar material visual na avaliação do aluno surdo, já que faz parte das acomodações necessárias para verificação da aprendizagem, uma vez que o surdo necessita dessa linguagem visual para poder interagir e construir significado. A Libras, naturalmente, ajuda o surdo a entender o que está sendo solicitado. Porém, também permanece vaga a ideia de como essas estratégias funcionaram para a aferição da aprendizagem.

Finalmente, a Professora Aline é a que mais se expande nas estratégias utilizadas: observações, atividades de sondagem com auxílio de figuras; jogos; brincadeiras e atividades de socialização. Destacamos as atividades com imagens, que são previstas por muitos pesquisadores. Em relação aos jogos, brincadeiras e atividades de socialização, ficamos também a imaginar como se deu o processo para a verificação da aprendizagem.

Após analisar as respostas dos professores, é natural retornar para nossa discussão teórica e observar que muitas propostas oferecidas pelos pesquisadores não constaram em suas entrevistas, como: em relação ao tempo de avaliação, ao formato das respostas, ao ambiente da avaliação e aos agrupamentos de alunos. De uma maneira geral, detiveram-se no formato da apresentação da avaliação, com o uso de imagens e da Libras e a adaptação curricular.

Outro aspecto sério, que nos chama a atenção, é o retorno da avaliação. Sabemos que a avaliação diagnóstica é o ponto de partida do trabalho pedagógico. Não houve menção ao trabalho realizado com base nas avaliações, nenhum direcionamento foi apontado, nenhum dado apresentado 
sob forma de reformulação de estratégias e obtenção de resultados positivos. Parece que tudo cessa no processo de avaliação. Esse, ao novo ver, é o problema maior. Escrita e reescrita são processos interdependentes. Se não há o retorno, a aprendizagem fica comprometida.

Na LDBEN (1996) no artigo 24, inciso V consta que a avaliação deve ser contínua e cumulativa em relação ao desempenho do aluno, com prevalência dos aspectos qualitativos sobre os quantitativos e dos resultados ao longo período sobre os de eventuais provas finais. Questionou-se aos participantes sobre os parâmetros por eles utilizados para avaliar um texto de um aluno surdo e um ouvinte.

Tabela 6 - Parâmetros utilizados para avaliar textos de alunos surdos e ouvintes.

\begin{tabular}{|l|l|}
\hline PROFESSORES & PARÂMETROS UTILIZADOS \\
\hline Carla & $\begin{array}{l}\text { Se o aluno surdo consegue sintetizar as ideias de um texto em Libras e } \\
\text { após isso fizer um texto escrito mesmo com dificuldades que possua vou } \\
\text { considerar o desenvolvimento como conquistado. } \\
\text { O aluno ouvinte vou avaliar levando em conta todas as normas é claro; } \\
\text { porém não quer dizer que não levo em conta a dificuldade que esse aluno } \\
\text { possa ter, mas a compreensão do texto é o principal. }\end{array}$ \\
\hline Bruno & $\begin{array}{l}\text { Sabendo que os alunos aprendem de forma diferente, em momentos } \\
\text { também diferentes, e que existem fatores externos e internos que } \\
\text { precisam ser levados em consideração, com os surdos não podia ser } \\
\text { diferente. Tais fatores são: conhecimentos prévios, família, experiência } \\
\text { em grupos da comunidade. }\end{array}$ \\
\hline Aline & O aluno que me refiro para essa pesquisa não produz texto. \\
\hline
\end{tabular}

Fonte: Elaborada pelas autoras, 2016.

A professora Aline apenas faz uma referência ao seu aluno que não produz texto, com isso omite a existência de parâmetros para avaliar a produção. Como não especifica, não podemos formular qualquer comentário a esse respeito. Apenas registrar que essa concepção já está superada. Só se aprende a produzir textos, produzindo. Hoje se propõe a construção a partir dos rabiscos. Isso também é viável para os surdos.

O professor Bruno apresenta como parâmetros os conhecimentos prévios, família, experiência em grupos da comunidade. Sabemos que tanto a leitura quanto a escrita se ancoram nos conhecimentos prévios, porém esses parâmetros variam bastante e dificultaria a aferição do texto. Os parâmetros precisam ter um alicerce mais linguístico. 
A professora Carla é a única que apresenta um parâmetro da avaliação da escrita dos surdos: o sentido. Suas tentativas de produzir significados na escrita, mesmo que as palavras sejam inadequadas e nem sempre redigidas da maneira convencional. Aqui tem-se um direcionamento textual, linguístico: o sentido de texto. Pelo menos com esse parâmetro é possível aferir sua aprendizagem na produção escrita de um texto.

Vê-se que, de uma forma geral, há apenas a oferta de um parâmetro para a avaliação do texto do aluno surdo.

A LDBEN (1996) prevê a integração dos alunos com necessidades especiais no sistema regular de ensino, porém muitos professores reclamam e dizem que não estão preparados para receber esses alunos. Frente ao exposto, julgou-se necessário questionar aos participantes como eles se autodefinem como avaliadores da produção textual do aluno surdo.

Tabela 7 - Como o professor se autodefine como avaliador da produção textual do surdo

\begin{tabular}{|l|l|}
\hline PROFESSORES & COMO O PROFESSOR SE AUTODEFINE \\
\hline Carla & $\begin{array}{l}\text { Não sinto dificuldade nenhuma. Às vezes sinto que o surdo tem muita } \\
\text { dificuldade em escrever também não só por conta da surdez em si, mas } \\
\text { por ser prático ao surdo a Libras. Porque aprender uma língua cheia de } \\
\text { regras se tenho uma língua que me identifica é muito mais fácil. Sinto } \\
\text { isso porque vejo a diferença dos textos de alunos surdos oralizados e } \\
\text { não oralizados. Os oralizados têm uma facilidade bem maior e os textos } \\
\text { apresentam uma maior coerência. Os não oralizados tem uma } \\
\text { dificuldade bem maior e sempre me questionam o porquê de terem que } \\
\text { aprender o português e como fica o texto em Libras. }\end{array}$ \\
\hline Bruno & $\begin{array}{l}\text { Pouco preparado para avaliação mais profunda. } \\
\text { universo do surdo. porque falta em mim maior conhecimento desse }\end{array}$ \\
\hline Aline
\end{tabular}

Fonte: Elaborada pelas autoras, 2016.

Pela resposta da professora Carla, não há dificuldade em avaliar o texto. Porém toda a resposta centrou-se na dificuldade do aluno. Avaliar requer um olhar para a ação de ensino. Em nenhum momento, houve um retorno de sua ação na superação da dificuldade do aluno em passar de uma estrutura oral para uma estrutura gestual. É natural pensar na ação de ensinar como a ação de vender. Só vendemos algo quando alguém comprou alguma coisa. Esse olhar da avaliação precisa ser reflexivo. 
Já os professores Bruno e Aline reconhecem que possuem dificuldade em avaliar uma turma com alunos ouvintes e surdos. Em conversa informal, após entrevista, foi comentado pelos professores que o que mais os preocupa é o fato de não saberem até onde o aluno entendeu o conteúdo, o tempo limite para a realização das atividades e provas e não poderem ofertar a mesma atenção aos ouvintes e surdos. Tudo isso os leva a se sentirem despreparados para avaliar as atividades em português do aluno surdo.

Aqui também chamamos atenção pois os professores demonstraram uma preocupação com os métodos de avaliação, como se a avaliação fosse um momento distinto e não parte do processo de aprendizagem. É uma outra lacuna que se apresenta.

Corrobora Vasconcelos (1998, p. 44) ao dizer que a avaliação é um processo que "implica uma reflexão crítica sobre a prática, no sentido de captar seus avanços, suas resistências, suas dificuldades e possibilitar uma tomada de decisão sobre o que fazer para superar os obstáculos". A argumentação de Vasconcelos serve tanto ao professor quanto ao aluno, ou seja, a prática pedagógica do professor deve ser refletida e revista constantemente, além de oportunizar ao aluno a percepção de seus progressos e a superação dos seus obstáculos.

\section{Conhecendo as vozes que produzem a escrita}

Um levantamento feito por Sena (2017) do perfil de uma escola de referência ao atendimento de alunos surdos da região metropolitana de João Pessoa. Aqui trazemos recortes da pesquisa com alunos surdos para dar voz à percepção deles sobre a língua portuguesa na sua vida escolar. Foram entregues 12 questionários, 5 (cinco) para sujeitos do sexo feminino e 7 (sete) para sujeitos do sexo masculino. Dos 12 alunos que receberam o questionário, apenas 9 (nove) responderam e devolveram.

Apresentamos nos Gráficos 1 e 2 sobre a faixa etária variada com distorção idade-série e o nível socioeconômico, para conhecermos os perfis dos sujeitos pesquisados. 
Gráfico 1- Perfil Idade / Série dos sujeitos pesquisado

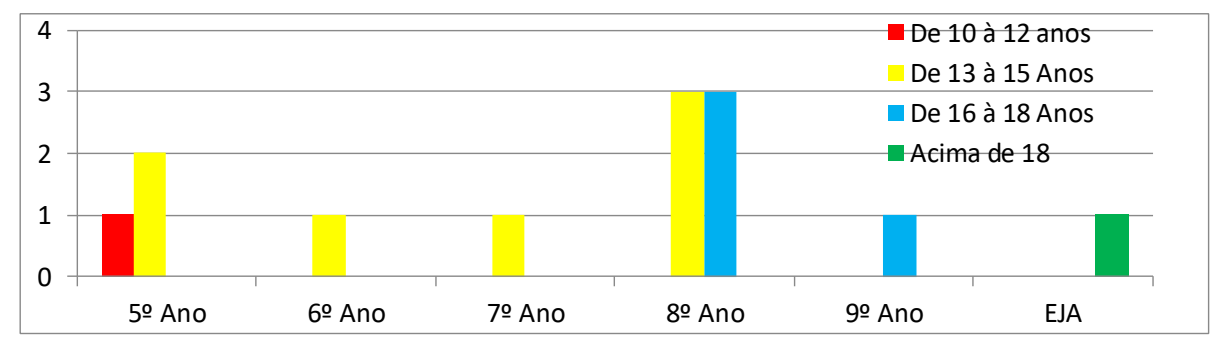

Fonte: Elaborado pelas autoras, 2017.

O aluno surdo apresenta essa distorção idade/série ${ }^{2}$, decorrente das dificuldades que encontra para avançar nos estudos na escola regular. Porém, um dos fatores que contribui para essa realidade é a falta de domínio da Libras ou sobre Libras, por parte dos professores da escola regular, que são os responsáveis pelo ensino, com vistas à aprendizagem dos alunos.

A realidade socioeconômica mostra que as famílias não ultrapassam a renda de três salários-mínimos. Acreditamos que esse fator também interfere no processo ensino aprendizagem.

Gráfico 2 - Perfil da situação socioeconômica dos sujeitos pesquisados

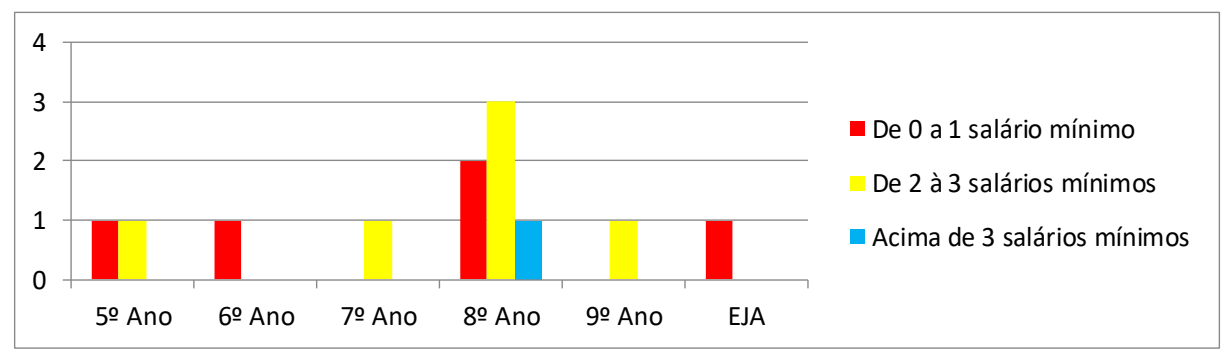

Fonte: Elaborado pelas autoras, 2017.

O ensino da língua portuguesa para surdos é um tema que vem ganhando espaço nos estudos atuais, tendo em vista a sua complexidade. Diante da temática perguntamos como o surdo considera o seu português,

\footnotetext{
${ }^{2} A$ distorção idade-série é o indicador educacional que permite acompanhar o percentual de alunos, em cada série, que têm idade acima da esperada para o ano em que estão matriculados. Disponível em: http://portal.inep.gov.br/.
} 
para facilitar a sua compreensão as alternativas foram de forma objetivas: ( ) Ruim; ( ) Bom; ( ) Médio; ( ) Ótimo.

Gráfico 3 - Avaliação do Português

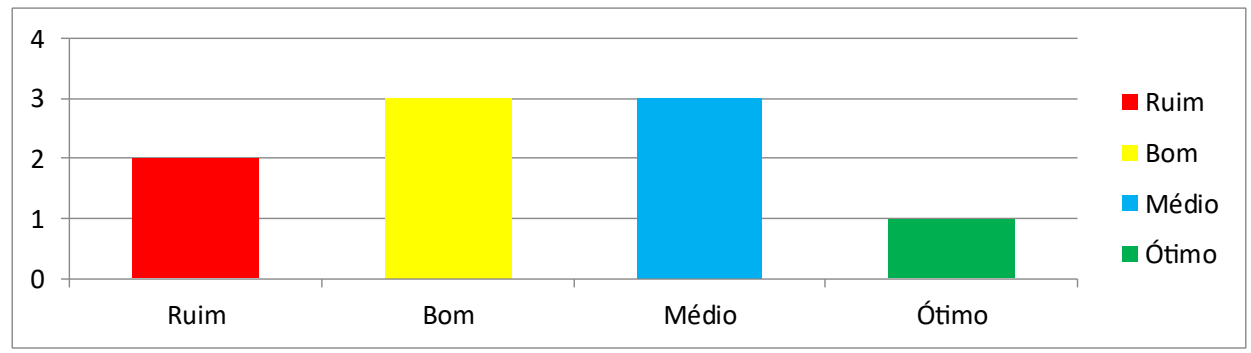

Fonte: Elaborado pelas autoras, 2017.

No gráfico 3, constatamos que em relação à avaliação do uso da $L 2,2$ (dois) alunos responderam que é ruim, 3 (três) responderam que é bom, 3 (três) acreditam que é médio e apenas 1 (um) respondeu que é ótimo. Vejam que há uma valoração mais positiva do que negativa. Eles são confiantes em sua proficiência na língua português.

Neste caso, percebemos que os surdos compreendem a língua portuguesa como necessária, uma vez que o uso da escrita faz parte do seu cotidiano, e se apresenta por meio de diferentes formas, em especial, podemos destacar a comunicação através do celular, utilizando-se de SMS, WhatsApp ${ }^{3}$, chats e e-mails, que oportunizam, de acordo com Sena, Matos e Cavalcante (2019), possibilidades de comunicação do sujeito surdo com os ouvintes, visto que essa nova forma de comunicação favorece não apenas a sua interação com os ouvintes, mas contribui também, para a realização de diversas atividades do dia a dia.

Também procurou-se entender, nessa pesquisa, quais dificuldades esses alunos apresentavam com a Língua Portuguesa. Novamente, usou-se uma forma objetiva para apresentar as necessidades especificadas, como analisaremos no Gráfico 4.

${ }^{3} \mathrm{O}$ WhattsApp é um software que apresenta uma interface atrativa e descomplicada, podendo ser utilizado para troca de mensagens instantâneas de textos, áudios e vídeos. 
Gráfico 4 - Nível de dificuldade na língua portuguesa

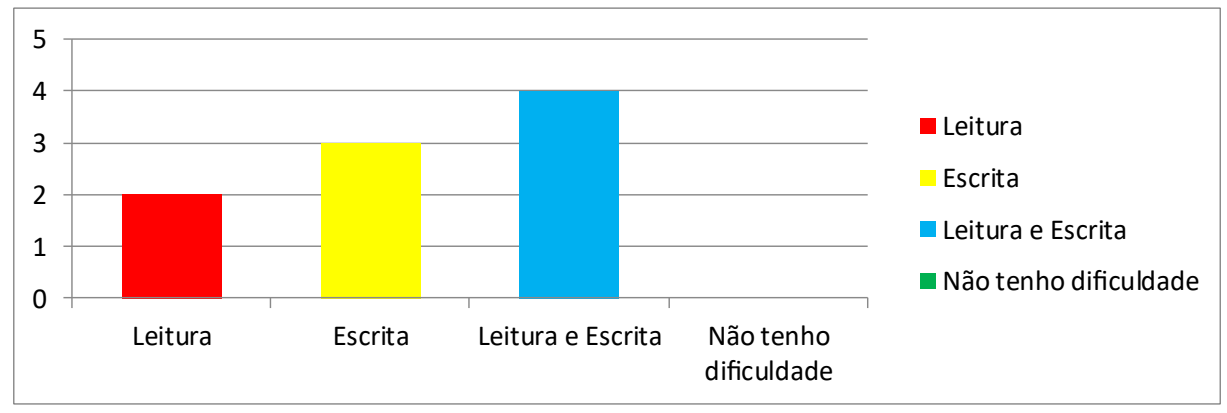

Fonte: Elaborado pelas autoras, 2017.

Nos dados analisados, 2 (dois) dos alunos pesquisados responderam que sentem dificuldade na leitura, 3 (três) informaram que sentem dificuldade na escrita e 4 (quatro) informaram que apresentam dificuldade tanto na leitura quanto na escrita. Essa dificuldade se dá, provavelmente, em virtude da afirmação de Quadros (1997, p. 111) que se posiciona acerca do assunto:

[...] o ensino de língua portuguesa para surdos sempre foi baseado no processo de alfabetização de crianças ouvinte. Os resultados desse tipo de ensino, indiscutivelmente, são considerados um fracasso: constata-se que a criança surda não atinge o domínio da língua portuguesa, a língua ensinada oralmente e graficamente durante o período em que a criança fica dentro da escola [...].

Certamente, isso ocorre devido à não adequação das metodologias e estratégias aplicadas para a alfabetização de ouvinte à criança surda. Desse modo, é necessário que, ao receber um aluno surdo na escola/sala de aula, o educador esteja atento às demandas trazidas por ele, para assim, adequar o currículo às necessidades existentes.

É notório o interesse apresentado por parte dos alunos surdos, quando trabalhadas atividades de leitura e escrita em sala de aula, certamente, isso acontece em conformidade com o posicionamento de Quadros (1997, p. 116) ao afirmar que "a leitura e a escrita são as possibilidades de ter acesso às informações de forma independente em uma sociedade onde ela faz parte de uma comunidade diferente", os surdos, certamente, percebem a importância da L2 para o seu dia a dia. 
Um outro levantamento importante com esse grupo de alunos foi sobre em que situações de uso eles precisam acessar a L2. Quando questionados acerca do uso da língua portuguesa para a realização de atividades do dia a dia, 8 (oito) dos 9 (nove) alunos pesquisados, afirmaram utilizar língua portuguesa para escrever mensagem via WhatsApp encaminhadas aos colegas, apenas 1 (um) aluno afirmou utilizar para outras finalidades, não especificando.

Gráfico 5 - Situação em que utiliza a língua portuguesa

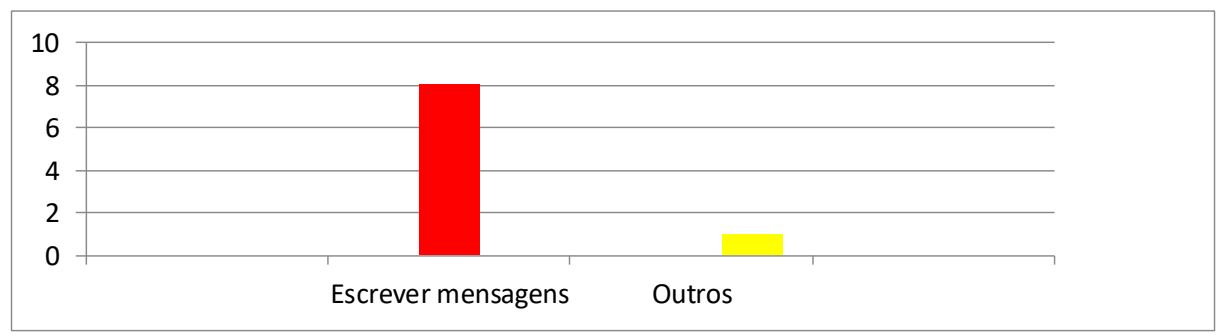

Fonte: Elaborado pelas autoras, 2017.

O surgimento das novas tecnologias e em especial do WhatsApp tem contribuído indiscutivelmente para a inserção do surdo nas relações sociais e interações com o grupo de ouvintes, facilitando a comunicação entre eles. Aqui percebemos a ligação com a resposta sobre a eficiência da língua portuguesa. Eles são eficientes no dia a dia, conseguem interagir pelo aplicativo, realizam os encontros, solucionam seus problemas cotidianos com o auxílio da língua portuguesa, fora da escola, daí a importância de pensar o ensino e aprendizagem da língua portuguesa como uma prática social importante para a construção do conhecimento, essa é uma demanda que concebe a escrita como uma modalidade da linguagem em consonância com a funcionalidade social.

Mas, por que a dificuldade se encontra na escola? Essa pergunta relaciona-se com o que foi discutido com os professores. Ensinar, avaliar a língua portuguesa do surdo requer uma outra visão que os professores ainda não compreenderam. 


\section{Costurando as vozes}

Durante a trajetória teórica da nossa pesquisa, buscamos fazer um estudo sobre a avaliação da Língua Portuguesa na educação de surdos, a fim de analisar as estratégias utilizadas pelos professores da rede pública municipal de Olinda e Paulista para a avaliação dos alunos surdos. Essa análise se deu a partir das entrevistas com professores de Língua Portuguesa que tinham alunos surdos em sala.

Foram colocadas questões de pesquisa: Que estratégias são utilizadas em sala de aula para avaliação do aluno surdo? Quais os retornos dessa avaliação? Como o professor se vê como avaliador da produção textual do surdo? Como o aluno surdo concebe a Língua Portuguesa e seu uso?

Primeiramente, vimos que as escolas inclusivas precisam se conscientizar de que a língua portuguesa é a L2 para o surdo e que essa deve ser ensinada como L2 e não como L1 como fazem com os alunos ouvintes tomando como base a oralidade. Já sabemos que o fracasso escolar do surdo está, muitas vezes, na forma como é conduzida a aprendizagem da leitura e da escrita da língua portuguesa.

Em relação às estratégias de avaliação vimos que se resumem a três: uso de imagens, da Libras e da adaptação ao currículo. Mesmo assim, não ficam claras como essas estratégias são utilizadas na sala de aula. Além disso, pela falta de retorno do que fazem com o resultado das avaliações, fica exposto um descompasso entre ensino e aprendizagem. É como se a avaliação fosse apenas somativa para indicar uma nota. Não há a reflexão do processo como um todo e isso compromete a aprendizagem da escrita.

Corroborando com as poucas estratégias utilizadas, a falta de parâmetros para a avaliação, pois foi apresentado apenas um aspecto linguístico, também concorre para que a dificuldade da aprendizagem na produção escrita seja superada.

Verificamos, também, que dois professores se definem como "despreparados" para avaliarem uma turma inclusiva. A que se disse preparada, pelo menos, não explicitou o processo da avaliação como ponto de partida para sua ação docente. Para os primeiros, o ato de avaliar esses alunos é extremamente complexo, é um verdadeiro dilema, que faz parte da sua vida escolar e que, posteriormente, transforma-se em desafio que eles terão de enfrentar, visto que a avaliação é algo indispensável ao processo de ensino e 
aprendizagem. Esse receio revela um desconhecimento mais profundo da teoria que resvala para a prática. E essa prática compromete intensamente a compreensão do processo da escrita pelo aluno surdo.

Essa insegurança precisa ser olhada pela gestão em todas as suas esferas: municipais, estudais e federais. $O$ professor é também vítima dessa estrutura educacional. Ele precisa ser atendido em suas reais dificuldades. Essa observação recai também sobre a formação inicial e continuada. As estratégias avaliativas precisam ser discutidas com mais profundidade nas universidades e nas formações de professores.

Colocar em prática critérios diferenciados de avaliação na escola significa reconhecer e respeitar a diferença linguística dos alunos surdos e evitar que ocorram discriminações e marginalização no contexto escolar. Consequentemente, um olhar diferenciado do professor nas produções escritas de alunos surdos é ponto de partida para concretizar, na prática, o diálogo com as diferenças, respeitando as possibilidades e limitações de seu aluno, para valorizar sua identidade surda.

Por outro lado, vimos o ponto de vista do surdo quando se refere à língua portuguesa: sentem-se seguros na vida cotidiana, mas inseguros na escola. A tarefa da escola é fazer o aluno surdo experienciar a língua portuguesa como L2, ampliar sua funcionalidade no dia a dia para que eles aprendam a amar e não a temer nossa língua.

Através desta pesquisa, foi possível perceber que os resultados obtidos nos levam a refletir acerca da importância de incentivar as discussões, fortalecendo o compromisso da escola para todos, dando espaço a um olhar diferenciado que vislumbre, em nossa sociedade, mudanças dos modelos existentes, que poderão ser iniciados pela nossa prática de sala aula, enquanto professores.

Constatamos que o respeito à condição linguística do surdo e a introdução de aulas e avaliações, visando práticas interdependentes e acessíveis, que atendam ao surdo em suas particularidades, também asseguram o desenvolvimento socioemocional do referido aluno, oportunizando o acesso da Libras e da Língua portuguesa e demais informações tanto curriculares como culturais, dando autonomia ao surdo frente à produção de diversas atividades diárias. 
As vozes vistas de lugares distintos cruzam-se na materialização da vida cotidiana. É necessário atravessá-las no espaço escolar. Para isso, todos nós somos chamados a dar uma contribuição.

\section{Referências}

AQUINO, José. O aluno, o professor e a escola. In: Passini, Elza; Malysz, Sandra; Passini, Romão (Orgs). Prática de ensino de geografia e estágio supervisionado. São Paulo: Contexto, 2007.

BARDIN, Laurence. Análise de conteúdo. São Paulo: Edições 70, 2011.

BATISTA, Antônio Augusto Gomes. Avaliação diagnóstica da alfabetização/ Batista. Antônio Augusto Gomes et al. Belo Horizonte: Ceale/FaE/UFMG, 2005. $88 \mathrm{p}$.

BOLSANELLO, Maria Augusta; ROSS, Paulo Ricardo. Educação especial e avaliação da aprendizagem na escola regular: caderno 2. Colaboradores: Urbanek, Dinéia at al. Universidade Federal do Paraná, Pró-reitora de Graduação e Ensino Profissionalizante, centro interdisciplinar de formação continuada de professores. Ministério da Educação, Secretaria de Educação Básica. Curitiba: Ed. da UFPR, 2005.

BRASIL. Lei no 9.394, de 20 de dezembro de 1996. Estabelecer as diretrizes e bases da educação nacional. Diário Oficial da União, 23 dez. 1996. Disponível em: www.planalto.gov.br/ccivil_03/LEIS/L9394.htm. Acesso em: 30 maio 2015.

BRASIL. Ministério da Educação. Estratégias para a educação de alunos com necessidades educacionais especiais / coordenação geral: SEESP/MEC; organização: ARANHA, Maria Salete Fábio. Brasília: Secretaria de Educação Especial, 2003.

BRASIL. Lei n. 10.436, de 24 de abril de 2004. Dispõe sobre a Língua Brasileira de Sinais - Libras e dá outras providências. Diário Oficial da União, $25 \mathrm{abr}$ 2004. Disponível em: http://www.planalto.gov.br. Acesso em: 13 maio 2015. 
BRASIL. Decreto de Lei 5.626, de 22 de dezembro de 2005. Regulamenta a Lei no 10.436, de 24 de abril de 2002, que dispõe sobre a Língua Brasileira de Sinais - Libras. Diário Oficial da União, 23 dez 2005. Brasília, DF. Disponível em: http//:www.planalto.gov.br. Acesso em: 05 maio 2015.

CAMILLO. Camila Righi M. Avaliação como dispositivo pedagógico. In: Thomas, Adriana da Silva e Klein, Madalena (Orgs.) Currículo \& Avaliação: a diferença surda na escola. Santa Cruz do Sul: EDUNISC, 2009. p.69-85.

FARIA, Evangelina Maria Brito de; ASSIS, Maria Cristina de. (Orgs.). Língua Portuguesa e Libras: teoria e prática. João Pessoa: Editora da UFPB, 2012.

HOFFMANN, Jussara Maria Lerch. Avaliação mediadora: uma prática em construção da pré-escola à universidade. Porto Alegre: Editora Mediação, 2009.

HOFFMANN, Jussara Maria Lerch. Avaliação mito e desafio: uma perspectiva construtivista. 43. ed. Porto Alegre: Editora Mediação, 2013.

LACERDA, C.B.F; LODI, Ana Cláudia Balieiro. A inclusão escolar bilíngue de alunos surdos: princípios, breve histórico e perspectivas. In: LODI. Ana Cláudia Broglia; LACERDA, Cristina Broglia Feitosa de. Uma escola, duas línguas: letramento em língua portuguesa e língua de sinais nas etapas iniciais de escolarização. 4. ed. Porto Alegre: Mediação, 2014. p. 11-32.

QUADROS. Ronice Muller. Educação de Surdos: a aquisição da Linguagem. Porto Alegre: Artmed Editora, 1997.

QUADROS, Ronice Müller de; Magali L. P. Schmiedt. Ideias para ensinar português para alunos surdos. Brasília: MEC, SEESP, 2006. 120 p.

RUSSEL, Michael K; AIRASIAN, Peter W. Avaliação em Sala de Aula: Conceitos e Aplicações. Tradução: ALMEIDA, Marcelo de Abreu; Revisão técnica: Fontanive, Nilma dos Santos; Rodrigues, Suely da Silva. 7. ed. Porto Alegre: AMGH, 2014. 
SENA, Fábia Souza de. O letramento do aluno surdo na escola regular:

Perspectivas e desafios.2017, 146p. Dissertação (Mestrado em Linguística e Ensino)- Programa de Pós-Graduação em Linguística, Universidade Federal da Paraíba, João Pessoa, 2017.

SENA, Fábia Souza de. Fábia Sousa de; MATOS, Denilson Pereira de; CAVALCANTE, Marianne Carvalho Bezerra. A utilização do WhatsApp como ferramenta motivadora no ensino de língua portuguesa para alunos surdos. Caderno Seminal Digital, v. 33, n. 33, 2019. p. 142-171.

SILVA, Soraya Gonçalves Celestino da. Avaliação da língua portuguesa para o aluno surdo: experiências em escolas públicas municipais de Pernambuco. 2015, 129 p. Dissertação (Mestrado em Linguística e Ensino) - Programa de Pós-Graduação em Linguística, Universidade Federal da Paraíba, João Pessoa, 2016.

SOUZA, Regina Maria de; GÓES, Maria Cecilia Rafael de. O ensino para surdos na escola inclusiva: considerações sobre o excludente contexto da inclusão. In SKLIAR, Carlos (Org.). Atualidade da educação bilíngue para surdos. v. 1, Porto Alegre: Mediação, 1999.

THOMA, Adriana da S; KLEIN, Madalena. Currículo e avaliação: a diferença surda na escola. Santa Cruz do Sul: Edunisc, 2009.

VASCONCELOS, Celso dos Santos. Avaliação da aprendizagem: Práticas de mudanças por uma práxis transformadora. 6. ed. São Paulo: Libertad, 1998.

VYGOTSKY, Lee Semenovich. A formação social da mente. São Paulo: Martins Fontes, 1991. 